$\underline{\text { Original Articles }}$

\title{
Deaths in a paediatric intensive care unit: A review over three years
}

\author{
Anant Khositseth ${ }^{1}$, Nattachai Anantasit ${ }^{1}$, Jarin Vaewpanich ${ }^{1}$
}

Sri Lanka Journal of Child Health, 2012; 41(4): 166-170

\begin{abstract}
Background: Deaths in paediatric intensive care units (PICUs) are sometimes unavoidable. The decision to withdraw or withhold treatment is important especially in places where there are limited resources.
\end{abstract}

Objective: To evaluate the modes of death and underlying diseases of patients' deaths in a PICU.

Method: We retrospectively reviewed the clinical features and management of consecutive nonsurvivors in the PICU at a tertiary care University Hospital in a developing country over a three-year period.

Results: Of 1,389 admissions, 110 (8\%) patients died. The median age of the deaths was 4.1 years. Most $(86 \%)$ patients had underlying diseases including congenital heart diseases (27\%) and malignancies $(23 \%)$. Forty-seven patients died with active treatment (AT), 60 died with life support limitation (LSL), and 3 had brain death (BD). The median length of stay (LOS) in AT group was 3 days and this was not significantly different $(p=0.056)$ from the median LOS in LSL group which was 5 days. LOS less than 3 days, postoperative cases and underlying diseases of the cardiovascular system were factors associated with the AT group. The three common complications leading to death were multi-organ failure, septicaemia with septic shock and respiratory failure.

Conclusions: Congenital heart diseases and malignancies were the two common underlying diseases found in non-survivors. LSL was the common mode of death in PICU.

(Key words: paediatric intensive care unit; mode of death; life support limitation; active treatment; brain death)

${ }^{1}$ Department of Paediatrics, Faculty of Medicine, Ramathibodi Hospital, Mahidol University, Bangkok, Thailand

(Received on 6 November 2011: Accepted after revision on 23 December 2011)
Introduction

Advanced intensive care and equipment have improved outcome of children admitted to paediatric intensive care units (PICUs). Reported mortality in a PICU has varied from $3.5-8.6 \%^{1-3}$ in the developed world compared to over $10 \%$ in developing countries. However, significant numbers of patients in PICUs were initially started with active treatment (AT) until the PICU team and parents met and decided on withdrawal or limited active treatment, though some patients underwent AT, including cardiopulmonary resuscitation (CPR), until death. The question of when to stop AT is somewhat difficult and ethical considerations are crucial in making such decisions. The objectives of this study were to evaluate the modes of death and underlying diseases of patients' deaths at a PICU in a developing country.

\section{Method}

Design: This is a retrospective review of medical records over a 3-year period.

Setting: This study was performed in the PICU of a University-based Tertiary/Quaternary Care Centre with a diverse patient population. The PICU is a 7 bedded unit which admits all patients younger than 15 years of age who require intensive care, including post-surgical patients but excluding neonates. The attending staff, including pulmonologist and cardiologist, rotated fortnightly and supervised the PICU team including paediatric residents, fellows in paediatric pulmonology and critical care, and nursing team with a nurse to patient ratio of $1: 1$.

Study period: Data was collected from January 1, 2007 to December 31, 2009.

Patient population: We included all patients admitted consecutively to the PICU during the study period who subsequently died. Patients already admitted to the PICU during the study period but who died after the study period, were excluded from the study. Regardless of the underlying diseases, patients were considered surgical if they were admitted within one week after operation whereas other patients were considered medical. 
Definition: Mode of death has been categorized as:

(i) Death following AT with failed CPR where unsuccessful attempts were made to resuscitate the patient including use of inotropic agents,

(ii) Do not resuscitate (DNR) (limited active treatment without CPR),

(iii) Withdrawal or withholding of life-sustaining treatment (WLST) where medical staff actively withdrew or withheld potentially life-sustaining medical treatment, such as mechanical ventilation or inotropic agents, and,

(iv) Brain death (BD) ${ }^{4}$.

For the purpose of comparison with other published studies, we included DNR and WLST in a single life support limitation (LSL) group but included BD in a separate group ${ }^{4}$.

\section{Statistical analysis}

Statistical analyses were performed using SPSS 13.0 for window software. Data was presented as median and inter-quartile ranges (IQRs) for continuous variables and as proportions (percentage) for categorical variables. Student's t- test was used for the comparison of continuous variables with a normal distribution, and the Kruskal-Wallis and MannWhitney tests were used for the variables without a normal distribution. Categorical variables were expressed as percentage values (e.g. frequency of LSL, frequency of deaths across hospitals) and were compared by using the chi-square test. Association tests were also performed for some variables that could influence the LSL decisions by using bivariate analysis. A p-value of $<0.05$ was considered statistically significant.

\section{Results}

Of 1,389 admissions, $110(8 \%)$ patients, $50 \%$ of them females, with a median age of 4.2 years (IQR $0.8-9.4$ years), died (were non-survivors) during the study period. Thirty-three $(30 \%)$ patients were less than 1 year of age. Most (83\%) patients had underlying diseases (Table 1) whereas 19 (17\%) patients presented with new episodes of diseases including dengue shock syndrome (5), acute hepatic failure (2), myocarditis (2), encephalitis (2), acute nonlymphoblastic leukaemia (2), wasp sting (1), drowning (1), cyanide poisoning (1), subdural haemorrhage (1), marasmus with colonic perforation (1) and invasive aspergillosis (1). Cardiovascular diseases $(27 \%)$ and malignancies (21\%) were the two most common underlying diseases (Table 1). The length of stay (LOS) from admission in PICU to death ranged from 1.5 hours to 122 days with a median LOS of 4 days (IQR 2 to 13 days). Twenty (11\%) patients died within 24 hours of admission to PICU. Concerning mode of death, 47 (42.7\%) patients died with AT, 60 (54.6\%) died with LSL and $3(2.7 \%)$ died with BD (Table 1$)$. The median LOS in the AT group (3 days, IQR 0.7- 8.8 days) was not significantly $(p=0.056)$ lower than that in the LSL group (5 days, IQR 3-14 days).

Table 1: Underlying diseases in patients with deaths

\begin{tabular}{|c|c|c|c|c|c|c|}
\hline \multirow{2}{*}{ Underlying diseases } & \multicolumn{3}{|c|}{ No. (\% mode of death) of pts } & \multirow{2}{*}{$\begin{array}{c}\text { No. of } \\
\text { pts }\end{array}$} & \multirow{2}{*}{$\begin{array}{l}\text { \% of } \\
\text { Total }\end{array}$} & \multirow{2}{*}{$\begin{array}{c}\text { LOS } \\
\text { (days) }\end{array}$} \\
\hline & AT & LSL & BD & & & \\
\hline Cardiovascular & $19(63.7)$ & $11(36.7)$ & $0(0)$ & 30 & 27.3 & 4 \\
\hline Oncologic & $09(39.1)$ & $14(60.9)$ & $0(0)$ & 23 & 20.9 & 5 \\
\hline None (New diagnosis) & $09(47.4)$ & $09(47.4)$ & $01(5.2)$ & 19 & 17.3 & 4 \\
\hline Liver & $04(44.4)$ & $05(55.6)$ & $0(0)$ & 09 & 8.2 & 0.75 \\
\hline Haematologic & $02(25)$ & $06(75)$ & $0(0)$ & 08 & 7.3 & 5 \\
\hline Pulmonary & $02(40)$ & $03(60)$ & $0(0)$ & 05 & 4.5 & 5 \\
\hline Immune deficiency & $0(0)$ & $04(100)$ & $0(0)$ & 04 & 3.6 & 7 \\
\hline Neurologic & $01(33.3)$ & $01(33.3)$ & $01(33.3)$ & 03 & 2.7 & 4 \\
\hline Renal & $0(0)$ & $03(100)$ & $0(0)$ & 03 & 2.7 & 7 \\
\hline Chromosome abnormality & $0(0)$ & $01(50)$ & $01(50)$ & 02 & 1.8 & 7 \\
\hline Gastrointestinal & $01(50)$ & $01(50)$ & $0(0)$ & 02 & 1.8 & 1.9 \\
\hline Inborn error of metabolism & $0(0)$ & $01(100)$ & $0(0)$ & 01 & 0.9 & 3 \\
\hline Juvenile rheumatoid arthritis & $0(0)$ & $01(0)$ & $0(0)$ & 01 & 0.9 & 3 \\
\hline Total & $47(42.7)$ & $60(54.6)$ & $3(2.7)$ & 110 & 100 & \\
\hline
\end{tabular}

$A T$, active treatment; $B D$, brain death; $L S L$, life support limitation; No., number; pts, patients

However, the percentage of LSL increased when the LOS was longer (Figure 1). Seventeen patients died followed operations including surgery for congenital heart diseases (12), bone marrow transplantation (3) and liver transplantation (2). 


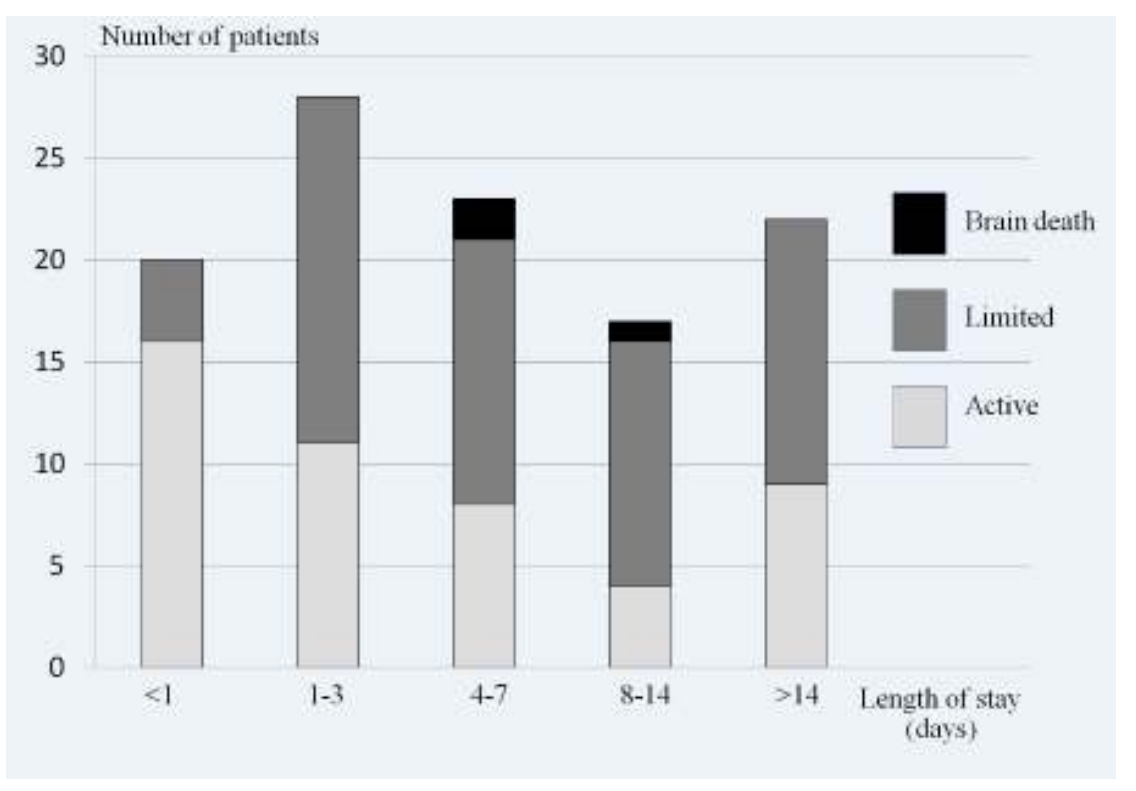

Figure 1: Proportional bar graphs demonstrated mode of deaths according to length of stay

Twelve patients had cardiac arrest prior to admission at PICU (Table 2). The median LOS in this group (2.5 days, IQR $3.7 \mathrm{~h}-4$ days) was significantly lower $(p=0.005)$ when compared to LOS in patients without prior cardiac arrest ( 5 days, IQR $2-14$ days). Five of
12 with prior cardiac arrest died with AT; however, the LOS was low, range from $1.5 \mathrm{hrs}$ to $11 \mathrm{hrs}$ when compared to the LOS in other 7 patients who died with LSL, range from $2-8$ days.

Table 2: Patients with prior cardiac arrest

\begin{tabular}{|c|c|c|c|c|c|c|c|}
\hline $\mathbf{P t}$ & Underlying disorder & $\begin{array}{c}\text { Age } \\
\text { (Years) }\end{array}$ & $\begin{array}{l}\text { Location of } \\
\text { cardiac arrest }\end{array}$ & Causes of cardiac arrest & $\begin{array}{l}\text { CPR } \\
\text { time }\end{array}$ & $\begin{array}{l}\text { LOS } \\
\text { (days) }\end{array}$ & $\begin{array}{c}\text { Mode } \\
\text { of } \\
\text { death }\end{array}$ \\
\hline 1 & Encephalitis & 11.8 & Ward & Displacement of ETT & 5 & 5 & LSL \\
\hline 2 & $\begin{array}{l}\text { Chromosome } 9 \text { duplicate } \\
\text { Pneumonia }\end{array}$ & 0.9 & ER after refer & $\begin{array}{l}\text { Tension pneumothorax } \\
\text { Delayed diagnosis }\end{array}$ & 20 & 8 & LSL \\
\hline 3 & $\begin{array}{l}\text { Dilated cardiomyopathy } \\
\text { Ventricular tachycardia, } \\
\text { Ventricular fibrillation }\end{array}$ & 0.9 & Ward & $\begin{array}{l}\text { Sudden cardiac death, } \\
\text { suspected arrhythmia }\end{array}$ & 75 & $3 \mathrm{hr}$ & AT \\
\hline 4 & Near drowning & 5.4 & Outside hospital & Near drowning & 40 & 4 & $\mathrm{BD}$ \\
\hline 5 & $\begin{array}{l}\text { Chronic diarrhoea } \\
\text { Shock }\end{array}$ & 0.3 & Other hospital & Hypovolaemic shock & 15 & 3 & LSL \\
\hline 6 & $\begin{array}{l}\text { Rhabdomyosarcoma } \\
\text { Dilated cardiomyopathy }\end{array}$ & 7.4 & Ward & $\begin{array}{l}\text { Unknown } \\
\text { (Suspected arrhythmia) }\end{array}$ & 20 & 2 & LSL \\
\hline 7 & Truncus arteriosus & 0.2 & Intraoperative & Low cardiac output state & 10 & $11 \mathrm{hr}$ & $\mathrm{AT}$ \\
\hline 8 & $\begin{array}{l}\text { Hypertrophic } \\
\text { cardiomyopathy }\end{array}$ & 0.2 & Ward & Secretion obstruction & 5 & 4 & LSL \\
\hline 9 & $\begin{array}{l}\text { Pulmonary atresia } \\
\text { Post left modified Blalock- } \\
\text { Taussig shunt }\end{array}$ & 0.1 & ER & $\begin{array}{l}\text { Hypoxic spell from shunt } \\
\text { dysfunction }\end{array}$ & 75 & $1.5 \mathrm{hr}$ & AT \\
\hline 10 & $\begin{array}{l}\text { Dextro-transposition of the } \\
\text { great arteries }\end{array}$ & 0.1 & ER & Severe hypoxia & 45 & $6 \mathrm{hr}$ & $\mathrm{AT}$ \\
\hline 11 & $\begin{array}{l}\text { Pulmonary atresia with } \\
\text { ventricular septal defect } \\
\text { Post left modified Blalock- } \\
\text { Taussig shunt }\end{array}$ & 2.3 & $\begin{array}{l}\text { Recovery room } \\
\text { after cardiac } \\
\text { catheterisation }\end{array}$ & Shunt obstruction & 60 & $3 \mathrm{hr}$ & AT \\
\hline 12 & $\begin{array}{l}\text { Inborn error } \\
\text { Dilated cardiomyopathy }\end{array}$ & 0.1 & ER & Ventricular tachycardia & 10 & 3 & LSL \\
\hline
\end{tabular}


Bivariate analysis demonstrated factors associated with AT, including LOS less than 3 days with an odds ratio of $2.2(95 \% \mathrm{CI}=1.0-4.7)$, postoperative case with an odds ratio of $5.11(95 \% \mathrm{CI}=1.5-16.9)$, and underlying diseases of cardiovascular system (CVS) with an odds ratio of $2.9(95 \% \mathrm{CI}=1.2-6.9)$ (Table 3$)$.

Table 3: Bivariate analysis of possible active treatment-associated factors

\begin{tabular}{|c|c|c|c|}
\hline Variables & Active Treatment (\%) & LSL (\%) & Odd ratio $(95 \% \mathrm{CI})$ \\
\hline \multicolumn{4}{|l|}{ Age } \\
\hline$<1$ year & $14(46.7)$ & $16(53.3)$ & 1.1 \\
\hline$\geq 1$ year & $34(43.6)$ & $43(56.4)$ & $(0.5-2.6)$ \\
\hline \multicolumn{4}{|l|}{ LOS } \\
\hline$\leq 3$ days & $27(55.1)$ & $22(44.9)$ & 2.2 \\
\hline$>3$ days & $21(36.2)$ & $37(63.8)$ & $(1.0-4.7)$ \\
\hline \multicolumn{4}{|c|}{ Underlying diseases } \\
\hline Yes & $38(42.7)$ & $51(57.3)$ & 0.6 \\
\hline None & $10(55.6)$ & $8(44.4)$ & $(0.2-1.7)$ \\
\hline \multicolumn{4}{|c|}{ Postoperative case } \\
\hline Yes & $13(76.5)$ & $4(23.5)$ & 5.11 \\
\hline No & $35(38.9)$ & $55(61.1)$ & $(1.5-16.9)$ \\
\hline \multicolumn{4}{|c|}{ Prior cardiac arrest } \\
\hline Yes & $5(50)$ & $5(50)$ & 1.3 \\
\hline No & $43(44.3)$ & $54(55.7)$ & $(0.3-4.6)$ \\
\hline \multicolumn{4}{|l|}{ CVS } \\
\hline Yes & $19(63.3)$ & $11(36.7)$ & 2.9 \\
\hline No & $29(37.7)$ & $48(62.3)$ & $(1.2-6.9)$ \\
\hline
\end{tabular}

The common complications were septic shock (26.4\%), acute renal failure (ARF) (22.7\%), congestive heart failure (CHF) (18.2\%), acute respiratory distress syndrome (ARDS) $(17.3 \%)$, liver failure $(10.0 \%)$, and cardiogenic shock $(8 \%)$.

\section{Discussion}

In developed countries, significant numbers of deaths in PICU followed withdrawal of life-sustaining medical treatment ${ }^{5}$. Most $(90 \%)$ adults in ICUs had mode of death of LSL whereas only $30-60 \%$ of children in PICU had mode of death of $\mathrm{LSL}^{6,7}$. Our study demonstrated the characteristics of children who died in a PICU in a tertiary care University Hospital in a developing country over a 3-year period. The mortality rate in this study was $8 \%$ which is higher than that reported in the United States and Europe $(4 \% \text { to } 6.2 \%)^{7-9}$, but comparable to that reported in Canada $(7.3 \%)^{10}$. Our study demonstrated that $87 \%$ non-survivors had underlying diseases of which $50 \%$ were cardiovascular diseases and malignancies. Twelve of 30 patients with cardiovascular problems were cases of post cardiac surgery who were transferred from the cardiac intensive care unit.

The median age of non-survivors was 4.2 years. This was higher than the median ages reported from other studies, ranging from 0.8 to 2.3 years ${ }^{6,7}$. This could be explained by the older age of our patients with malignancies in this study. The median length of time from admission in PICU to death was 4 days which was higher than those reported from other studies, which had a range of $2-3$ days $^{8,11}$.

A review of published studies demonstrated that there is considerable variation of the proportion of mode of death of LSL from $18-74 \%{ }^{4}$. LSL as a mode of death was more common in North America and Europe (3065\%) than in South America (18-32\%). Interestingly, one report from a centre in Australia reported LSL as a mode of death in $74 \%{ }^{4}$. LSL as a mode of death in our study was $55 \%$ which was comparable to that in North America and Europe. Factors determining the incidence of mode of death of LSL were type of ICU, patients' age, the varieties of cases, the underlying diseases, attitudes of the attending clinical teams, the difference in cultures, the country regions, and the policies of admission and discharge in each PICU. In this study, LOS less than 3 days, presence of postoperative cases and underlying diseases of cardiovascular system were factors that correlated with AT. Initially in PICU, active management is needed to maintain and stabilize critically ill patients in the hope that patients would survive and fully recover. The question of when to stop active management is still controversial. In our centre we did not have a general policy in determining LSL. 
Each individual case was discussed between the attending staff, clinical team members along with parents of the patient when a patient's condition deteriorated or did not improve over a period of time. We suggest that regular communication about patients' conditions and discussion of plans for management with their parents are the important key factors. Eventually, when patients' conditions deteriorated beyond survival, end-of-life care and humanized medicine are now widely accepted forms of management. LSL has been increasing in medical practice to avoid the use of treatments that only prolong life but do not improve patient outcome, usually leading to useless treatments and needless suffering.

\section{Conclusions}

In a PICU of a developing country, LSL was still the common mode of death. Congenital heart disease and malignancies were the two common underlying diseases found in non-survivors. LOS less than 3 days, presence of postoperative cases, and underlying diseases of CVS were factors determining active treatment.

\section{References}

1. Han YY, Carcillo JA, Venkataraman ST, Clark RS, Watson RS, Nguyen TC, et al. Unexpected increased mortality after implementation of a commercially sold computerized physician order entry system. Pediatrics 2005; 116(6): 1506-12. http://dx.doi.org/10.1542/peds.2005-1287

2. Leclerc F, Leteurtre S, Duhamel A, Grandbastien B, Proulx F, Martinot A, et al. Cumulative influence of organ dysfunctions and septic state on mortality of critically ill children. American Journal of Respiratory and Critical Care Medicine 2005; 171(4): 348-53. http://dx.doi.org/10.1164/rccm.200405-630OC

3. Del Beccaro MA, Jeffries HE, Eisenberg MA, Harry ED. Computerized provider order entry implementation: no association with increased mortality rates in an intensive care unit. Pediatrics. 2006; 118(1): 290-5. http://dx.doi.org/10.1542/peds.2006-0367
4. Moore P, Kerridge I, Gillis J, Jacobe S, Isaacs D. Withdrawal and limitation of life-sustaining treatments in a paediatric intensive care unit and review of the literature. Journal of Paediatrics and Child Health. 2008; 44(7-8): 404-8. http://dx.doi.org/10.1111/j.14401754.2008.01353.x

5. Roy R, Aladangady N, Costeloe K, Larcher V. Decision making and modes of death in a tertiary neonatal unit. Archives of Disease in Childhood Fetal and Neonatal Edition 2004; 89(6): F527-30. http://dx.doi.org/10.1136/adc.2003.032912

6. Garros D. [A "good" death in pediatric ICU: is it possible?]. Jornal de Pediatria (Rio J) 2003; 79 Suppl 2: S243-54. http://dx.doi.org/10.2223/JPED.1101

7. Devictor DJ, Nguyen DT. Forgoing lifesustaining treatments in children: a comparison between Northern and Southern European pediatric intensive care units. Pediatric Critical Care Medicine 2004; 5(3): 211-5. http://dx.doi.org/10.1097/01.PCC.0000123553.2 2405.E3

8. Vernon DD, Dean JM, Timmons OD, Banner W, Jr., Allen-Webb EM. Modes of death in the pediatric intensive care unit: withdrawal and limitation of supportive care. Critical Care Medicine 1993; 21(11): 1798-802. http://dx.doi.org/10.1097/00003246-199311000$\underline{00035}$

9. Zawistowski CA, DeVita MA. A descriptive study of children dying in the pediatric intensive care unit after withdrawal of life-sustaining treatment. Pediatric Critical Care Medicine 2004; 5(3): 216-23.

http://dx.doi.org/10.1097/01.PCC.0000123547.2 $\underline{8099.44}$

10. Garros D, Rosychuk RJ, Cox PN. Circumstances surrounding end of life in a pediatric intensive care unit. Pediatrics 2003; 112(5): e371. http://dx.doi.org/10.1542/peds.112.5.e371

11. Mink RB, Pollack MM. Resuscitation and withdrawal of therapy in pediatric intensive care. Pediatrics 1992; 89(5): 961-3. 